\title{
Editorial: Proceedings of the 29th International Congress for Conservation Biology (ICCB 2019)
}

\author{
Leslie Cornick $^{1 *}$ and John A. Cigliano ${ }^{2}$ \\ ${ }^{1}$ School of STEM, University of Washington Bothell, Bothell, WA, United States, ${ }^{2}$ Cedar Crest College, Allentown, PA, \\ United States
}

Keywords: biodiversity, conservation, post-pandemic, ICCB, environmental justice

\section{Editorial on the Research Topic}

Proceedings of the 29th International Congress for Conservation Biology (ICCB 2019)

\section{OPEN ACCESS}

Edited and reviewed by: Orsolya Valkó, Hungarian Academy of Science, Hungary

*Correspondence: Leslie Cornick Icornick@uw.edu

Specialty section: This article was submitted to Conservation and Restoration Ecology,

a section of the journal Frontiers in Environmental Science

Received: 01 February 2022 Accepted: 01 February 2022

Published: 16 February 2022

Citation: Cornick L and Cigliano JA (2022) Editorial: Proceedings of the 29th International Congress for Conservation Biology (ICCB 2019).

Front. Environ. Sci. 10:867403 doi: 10.3389/fenvs.2022.867403
The Society for Conservation Biology's International Congress for Conservation Biology (ICCB) is a global forum for addressing conservation challenges and for presenting new research in conservation science and practice. ICCBs are recognized as one of the most important international meetings for conservation professionals and practitioners. Attendees include scientists, students, managers, policy-makers, writers, educators and other conservation professionals from throughout the world. These Proceedings showcase some of the work presented at the 29th ICCB held in Kuala Lumpur, Malaysia from 21 to 25 July 2019.

The theme of this Congress was Conservation beyond Boundaries: Connecting Biodiversity with Communities, Governments and Stakeholders. This theme recognized the challenges of conserving biodiversity across political and cultural boundaries. Biodiversity does not recognize human-drawn boundaries, but the latter can have major impacts on the biosphere through social, political and economic structures. Conserving biodiversity beyond boundaries requires communication and collaboration among countries, government agencies, NGOs, and communities, and across fields of knowledge because threats to species and ecosystems reach beyond such boundaries.

Each ICCB focuses on several organizing themes to frame the critical Research Topics in biodiversity conservation and to bring together multidisciplinary scientists, practitioners, advocates, social scientists, students, public officials, and the media to explore every facet of threats to biodiversity and their potential solutions. The themes for this ICCB included:

- Connecting the efforts of scientists, academics and practitioners with communities, governments, businesses and other stakeholders

- Maximizing equity, inclusion, and diversity in the field

- Nurturing the next generation of conservation professionals

- Engaging emerging and critical conservation Research Topics

- Transcending boundaries through global networking

- Providing professional development opportunities and closing the skills gap in developing countries

- Utilizing technological innovation and advancements to conserve natural resource

- Making an impact by mobilizing local community participation in conservation efforts

The unique multidimensional nature of the ICCB creates synergies that science-only meetings rarely achieve. This special Research Topic in Frontiers is a small collection of papers that were presented at the Congress. Our goal for this Research Topic is to not only highlight some examples of great work being done in biodiversity conservation but also to identify any needs/gaps. The open- 
access Research Topic contains eight publications with 35 authors that have received over 21,000 reads across the globe.

And as we reflect on the Congress in the third wave of the COVID-19 pandemic and the emergence of the Omicron variant, we are compelled to consider what biodiversity conservation might - and must - look like for a post-pandemic planet, and for a world still engulfed in the challenges and geopolitical landscape around global climate change, international social and racial justice reckonings, and the fight for global democracy amid a resurgence of authoritarian dictatorship.

\section{SELECTED ICCB 2019 PUBLICATIONS}

These Proceedings include eight publications with 35 authors, with over $21 \mathrm{k}$ views across the globe. These papers cover a broad range of topics and approaches to conserving biodiversity. Several studies follow a more traditional, ecological approach to conservation. Simpson et al. compared the use of artificial salt licks by mammals to nearby forested sites in Malaysia. Using camera traps, they found that 23 species of mammals used the salt licks, compared to 19 mammals in the forest. The authors suggest that artificial salt licks could be used to diversify and enrich habitats where natural mineral licks have been lost. Rege et al. also studied habitat use by mammals. In this study, the authors looked at how mammals used mixed forest-cashew landscape in the northern Western Ghats of India. Also using camera traps, this preliminary study found that of the 11 species found using the forests, nine were also detected in cashew plantations. Of these nine species, four were found more frequently in the cashew plantations. The authors suggest that their study highlights the need for more research on the use of forest-cashew landscapes to assess conservation opportunities. Roads can lead to conservationrelated Research Topic, such as habitat fragmentation and degradation, increased legal and illegal exploitation, and roadkills. Hui et al. argue that more studies are needed on the extent of roadkills, and ways to reduce them in Malaysia. The authors measured the species richness and abundance of vertebrate roadkills on highways that went through four habitat types in Malaysia. The authors found that roadkill consisted of a total of at least 24 species, three of these are protected species in Malaysia. The most important finding was that most roadkills were found near vegetation cover and water bodies in all habitats. The authors suggest that roadkills can be minimized by changing the structure and composition of roadside vegetation and other landscape features to discourage wildlife from aggregating near roads.

Conservation is an interdisciplinary endeavor and this fact is exemplified by the next two papers in this Special Research Topic. One of the most well-attended symposia in the history of the ICCB was the plenary panel on Faith and Conservation in Dialog, where we hosted Christian, Buddhist, Muslim, and Indigenous faith leaders to discuss the role of faith communities in the conservation of global biodiversity. Schaefer et al.expanded on this critical work and discussed the need to identify ways for conservation scientists and practitioners to work collaboratively and respectfully with faith leaders and communities to advance conservation outcomes. Blount-Hill and Odor take a unique look at human-wildlife conflict. The authors suggest that humanwildlife conflict should be considered more than individuallevel interactions that negatively affect humans, wildlife, or both and should be looked at as competition for resources between groups (human vs. non-human). The authors further argue that, relying on social dominance theory, the same sociopolitical power structures that marginalize human groups could also be the cause of similar marginalization and neglect of wildlife species, and that understanding human-wildlife conflicts in this way could lead to new perspectives in conservation.

While much conservation work is done in the "wild," significant contribution to conservation can be made in other places. For example, urban green spaces can offer a wide range of benefits to urban communities and the environment. However, for green spaces to be effective, they must be part of national policy and city-planning strategies, argue Afionis et al., especially in sub-Saharan Africa, which is undergoing rapid urban expansion. The authors focused on Malawi, one of the most rapidly urbanizing countries in the region, and found that greenspaces were not integrated into the planning process at the national-level but were a priority at the city-level. Zoos and aquariums can also be important to conservation. Ripple et al. describe the Saving Animals From Extinction (SAFE) program of the Association of Zoos and Aquariums (AZ) as an example of how these institutions contribute to the conservation of biological diversity.

\section{THE IMPACT OF THE COVID-19 PANDEMIC}

One of the most significant setbacks in the conservation of biodiversity in the last 100 years has been the impacts of the COVID-19 pandemic on communities, scientific research, increased pressure on natural resources and wildlife poaching, and reduced vigilance towards protecting biodiversity. Communities in developing countries already have significant economic disparities that result in inequitable access to national economies, healthcare, family planning, and education. The COVID-19 pandemic amplified these inequities at scales not seen since the 1918 global flu pandemic. Bates et al. (not part of this Research Topic) describe how shifts in human mobility during the pandemic have created both positive and negative outcomes for biodiversity, but the long-term impacts are yet to be determined as new variants emerge, economies shift towards unsustainable mining and other extractive practices to mitigate increased demand and supply chain shortages, and governments shift priorities away from conservation to economic rescue and/or growth. The ongoing threats to democracy and democratic principles in the United States and globally portend potential increases in authoritarian rule, especially in countries where severe economic downturns brought on or exacerbated by the pandemic cut off conservationists from having input into government decision making. As entire countries shut down sectors of their economies and rural-based families lost urban employment opportunities, many were forced to return to rural lifeways that increased reliance on limited natural resources.

As we consider the post-pandemic "new normal" for communities, countries, and the globe, we must include biodiversity conservation 
in those critical conservations. One of the most effective venues for these multidimensional, multidisciplinary, and multistakeholder conversations is the ICCB. It is incumbent on all of us who participate in conservation at every level to ensure that the voices of biodiversity are not only again heard, but are amplified as we create that new normal in a context of social, racial, and environmental justice. We fail at our peril.

\section{AUTHOR CONTRIBUTIONS}

All authors listed have made a substantial, direct, and intellectual contribution to the work and approved it for publication.
Conflict of Interest: The authors declare that the research was conducted in the absence of any commercial or financial relationships that could be construed as a potential conflict of interest.

Publisher's Note: All claims expressed in this article are solely those of the authors and do not necessarily represent those of their affiliated organizations, or those of the publisher, the editors and the reviewers. Any product that may be evaluated in this article, or claim that may be made by its manufacturer, is not guaranteed or endorsed by the publisher.

Copyright (๑) 2022 Cornick and Cigliano. This is an open-access article distributed under the terms of the Creative Commons Attribution License (CC BY). The use, distribution or reproduction in other forums is permitted, provided the original author(s) and the copyright owner(s) are credited and that the original publication in this journal is cited, in accordance with accepted academic practice. No use, distribution or reproduction is permitted which does not comply with these terms. 